\title{
O Abortamento Conforme o Direito Comparado e a Teoria Feminista
}

\begin{abstract}
Abortion According to Comparative Law and the Feminist Theory
Bruna Santana da Encarnação ${ }^{1 *}$, Anna Laura Maneschy Fadel ${ }^{1}$, Andréa Cristina Marques de Araújo $^{1}$

RESUMO

O presente artigo visa debater a legalização do abortamento no Brasil, visto que a legislação brasileira sobre o assunto é obsoleta, pois mesmo com a criminalização da prática, as brasileiras continuam abortando, porém de forma insegura. Para tanto, utilizou-se o método dedutivo, ou seja, através da leitura de materiais previamente existentes, buscou-se embasar a legalização do aborto como expressão da autonomia da mulher e de seus direitos sexuais e reprodutivos, além de analisar, nesse âmbito, como o racismo afeta as mulheres negras que desejam abortar. Como referencial teórico, utilizou-se principalmente a professora Flávia Biroli e suas produções sobre a Teoria Feminista. Ademais, fez-se uso do Direito Comparado para fundamentar a discussão, visto que vários países já possuem legislações modernas sobre a temática. Por fim, conclui-se que o aborto deve ser legalizado, pelo menos, até o primeiro trimestre da gestação indesejada, como forma de sopesar os direitos da mulher em contraste com a possível vida de um feto, principal argumento usado por aqueles que são contra o abortamento. Concluiu-se que a legalização do abortamento é fundamental para a democracia, bem como se observa que há violência racial em se tratando de abortamento seguro.
\end{abstract}

Palavras-chave: Abortamento; Autonomia; Legalização; Direito Comparado; Teoria Feminista.

\begin{abstract}
This article aims to debate the issue of the abortation legalization in Brazil, since Brazilian legislation is obsolete on that aspect, because even with the criminalization of the practice, Brazilian women continue to abort, but in an unsafe way. Hence, the deductive method was used, that is, through the reading of previously existing materials, we sought to base the legalization of abortion as an expression of women's autonomy and their sexual and reproductive rights, in addition to analyzing, in this context, how racism affects black women who wish to abort. As theoretical reference, it was used mainly the professor Flávia Biroli and her productions on the Feminist Theory. Furthermore, Comparative Law was used to support the discussion, as several countries already have modern legislation on the subject. We concluded that abortion should be legalized, at least, until the first trimester of the unwanted pregnancy, as a way to weigh women's rights against the possible life of a fetus, the main argument used by those who are against abortion. Finally, we also concluded that the legalization of abortion is fundamental for democracy, as well as that there is racial violence when it comes to safe abortion.
\end{abstract}

Keywords: Abortation; Autonomy; Legalization; Comparative Law; Feminist Theory.

\footnotetext{
${ }^{1}$ Centro Universitário do Estado do Pará - CESUPA, Campus de Direito, Belém-PA, Brasil.

*E-mail: brunasantana.academico@gmail.com
} 


\section{INTRODUÇÃO}

O abortamento é uma temática bastante controversa, principalmente no tocante a sua legalidade, assim como as discussões morais que circundam o debate. Não obstante, essa questão não é novidade nas discussões jurídicas, sendo recorrentemente o tema de julgamentos muito acalorados, os quais envolvem, principalmente, os direitos reprodutivos da mulher em face aos possíveis direitos que o feto terá se nascer com vida.

Dessa forma, ressalta-se que alguns países já legalizaram a prática sem qualquer tipo de circunstância que tenha que ser comprovada para a mulher, como os Estados Unidos, e outros que permitem o abortamento em apenas situações específicas, sendo o Brasil um exemplo destes. Ademais, há países que proíbem o aborto em qualquer condição, como o caso de El Salvador. Assim, em primeiro momento, é necessário que seja trazido à baila como outros países lidam com essa prática, com o intuito de respaldar a necessidade da legalização do abortamento no Brasil.

Na primeira seção deste artigo, será feito um breve histórico sobre o abortamento e, após, será analisado como se dá o funcionamento das legislações sobre o abortamento em dois Estados que já o legalizaram: os Estados Unidos e o Uruguai. Esse estudo se faz necessário em razão das legislações dos países observados serem modernas e eficientes, além de respeitarem a autonomia da mulher e, portanto, é interessante que o Brasil as considere em seu debate sobre legalização do abortamento.

Na segunda parte, em uma expressiva discussão sobre o abortamento, tal qual o presente artigo visa, é basilar que se argumente o debate em torno da figura da mulher e da Teoria Feminista, isto é: quais são seus Direitos Humanos e Fundamentais? A vida de uma mulher pode ser equiparada à presença de um feto em seu útero? A legislação brasileira se mostra adequada à mulher do século XXI? Dessa forma, será analisada a colisão de direitos, bem como também será debatida a emancipação da mulher, que urge pela observação da autonomia individual feminina, fundamental para uma democracia.

Além dessas proposições, serão apresentadas e refutadas as questões que versam a favor do feto, principalmente as com fulcro na religiosidade conservadora presente no Brasil, visto que essa negligencia a existência e o sofrimento da mulher que gesta um feto não desejado.

Por fim, o estudo será concluído demonstrando que a legalização e uma nova legislação sobre o abortamento são imperiosas para o Estado brasileiro, visto que essa 
prática é uma questão não só de saúde pública, mas de democracia, pois o abortamento é recorrente no Brasil, apesar de ser criminalizado e, assim, é realizado de forma insegura e, portanto, macula a decisão da mulher.

Dessa forma, o artigo foi dividido em três partes: a primeira trata sobre o histórico da prática, com o intuito de situar o leitor, a segunda foca na análise do Direito Comparado e da legislação brasileira vigente e, por fim, será vista a importância da autonomia da mulher e de questões relacionadas a religião e raça, tal como estuda a Teoria Feminista.

\section{METODOLOGIA}

Como metodologia, usou-se o método dedutivo, isto é, por intermédio de materiais preexistentes, tal qual livros, artigos acadêmicos, sites de notícias e entre outros, visou-se embasar coerentemente as discussões sobre a temática. Para isso, tomase como referência principal o artigo da professora Flávia Biroli denominado de “Autonomia e justiça no debate sobre o aborto: implicações teóricas e políticas". Desse modo, a pesquisa bibliográfica e documental foi a principal fonte para embasar as conclusões do artigo.

Por último, destaca-se que, igualmente, fara-se presente a análise de legislações e jurisprudências, tanto brasileiras quanto internacionais. No tocante ao Direito, igualmente, deu-se ênfase aos ramos Constitucional, Penal e aos Direitos Humanos.

\section{HISTÓRICO DO ABORTAMENTO}

O abortamento é uma prática que já era realizada desde a antiguidade. À título de exemplo, na Grécia Antiga, o aborto era tido como uma forma de controle populacional, sendo, inclusive, recomendado pelo filósofo Aristóteles. Platão, por sua vez, também defendia a prática do aborto, principalmente para as mulheres a partir dos 40 anos, pois, para ele, o abortamento teria viés eugênico e seu objetivo primordial era manter a qualidade dos guerreiros gregos (SCHOR; ALVARENGA, 1994).

Assim, por razões condizentes com o que hoje é buscado através da legalização do abortamento, Sócrates recomendava que as parteiras, tal como sua mãe, ajudassem as mulheres que quisessem abortar, ou seja, pode-se ver que Sócrates já percebia a 
autonomia das mulheres sobre seu próprio corpo. Ressalta-se, evidentemente, que em nenhuma hipótese se busca a legalização do aborto como forma de controle populacional ou por razões eugênicas, tal como os filósofos Aristóteles e Platão defendiam.

Por outro lado, no século XIX, a Igreja Católica condenava tanto o abortamento quanto outros métodos contraceptivos, visto que, para ela, a alma está intrínseca ao embrião, ou seja, a Igreja Católica vê a questão, somente, do ponto de vista do feto e, portanto, ignora a autonomia da mulher. Ressalta-se que esse pensamento não mudou muito até os dias atuais, apesar de os métodos contraceptivos serem aceitos, o aborto ainda é considerado por ela como um homicídio, conforme o mandamento cristão "Não Matarás”. Entretanto, é fato que já existem movimentos singelos dentro dessa igreja que enxergam a temática sob a perspectiva da mulher.

Em contrapartida, no século XX, mais especificamente entre as décadas de 1960 e 1970, que o movimento feminista, atrelado à descoberta da pílula anticoncepcional, iniciou a distinção entre a maternidade e a sexualidade. Sobre os direitos reprodutivos, a filósofa Angela Davis (2016 [1981]) dispõe que na década de 1970, o abortamento legal e de acesso fácil era um tema tão controverso quanto a "maternidade voluntária" e, ademais, ela ressalta que o abortamento, quando necessário, é um pressuposto basilar para a emancipação das mulheres.

Ao seu turno, bell hooks (2020 [2000], p.50), no mesmo contexto da emancipação feminina americana entre as décadas de 1960 e 1970, atenta que: “[...] estava claro para nós que não poderia haver qualquer libertação sexual genuína para mulheres e homens sem melhores e mais seguros métodos contraceptivos - sem o direito ao aborto seguro e legal". Portanto, infere-se que a questão do abortamento legal é um direito reprodutivo indispensável à mulher.

Hodiernamente, de acordo com dados de 2012 da Organização Mundial de Saúde (2012, apud Flávia Biroli, 2014), cerca de 22 milhões de mulheres realizam abortos inseguros anualmente. Um número bem expressivo para uma estimativa, já que ocorre a subnotificação desses abortamentos em razão dele ser criminalizado em diversos países.

Em âmbito brasileiro, como será pormenorizado, vê-se que o debate feminista majoritário segue a mesma linha de raciocínio do feminismo internacional do início da década de 1970, isto é, mostra-se favorável ao abortamento, pois esse faz parte dos direitos das mulheres, principalmente os individuais (SCAVONE, 2008). 
Após esta breve análise do histórico do abortamento, passa-se a analisar, sob a égide do Direito Comparado, como funciona a legalização do aborto em alguns países, com o intuito de corroborar tal legalização no Brasil, já que como apontado por Biroli (2014), a ilegalidade do abortamento não reflete a realidade social das mulheres diante do aborto e, portanto, permite comparar essa proibição de hoje com a restrição ao divórcio anterior a 1977 no Brasil.

\section{DIREITO COMPARADO: LEGISLAÇÕES SOBRE ABORTAMENTO PERTINENTES AO ESTUDO}

De acordo com o mencionado anteriormente, serão analisadas no presente artigo duas legislações internacionais que se originaram, principalmente, através dos movimentos feministas, legalizando a prática como forma de respeitar a autonomia da mulher, direito esse que é basilar em um Estado democrático.

O estudo será iniciado com os Estados Unidos, a principal referência da temática em âmbito mundial e, após, será analisado a legislação do Uruguai, visto que este, como o Brasil, é um país latino-americano e, apesar de ter legalizado o aborto mais tardiamente, já se mostra como uma sólida referência no debate sobre abortamento.

Preliminarmente, pode-se constatar que nas legislações analisadas, alguns pontos são convergentes, como o fato de que essas buscam respeitar a autonomia da mulher e, igualmente, reconhecem que a criminalização do abortamento não é eficiente, já que mulheres abortam independentemente dessa tipificação. Apesar disso, também foi constatado que o período em que a realização do abortamento foi legalizada diverge entre os países.

\section{ESTADOS UNIDOS}

Entre todos os países que permitem a prática do aborto, os Estados Unidos são, sem dúvidas, a principal referência no assunto e, portanto, a análise de sua legislação é essencial. A Constituição Americana, por sua vez, não traz, em seu texto, normas diretamente relacionadas ao tema do abortamento, assim, foi em 1973 que a temática foi analisada pela Suprema Corte dos Estados Unidos, mais especificamente com o caso Roe v. Wade. 
Até a década 1960, o aborto era ilegal nos Estados Unidos e, da mesma forma como hoje ocorre no Brasil, as mulheres realizavam o abortamento em clínicas clandestinas ou, quando mais abastadas, viajam para países em que a prática era legalizada. Dessa forma, observou-se que as mudanças nas leis contra o abortamento nos estados americanos começaram a mudar no fim da década supramencionada, com estados como Nova York abrindo exceções para a prática ou, até mesmo, legalizando-a.

Apesar disso, na maioria dos estados americanos, as mulheres ainda eram impedidas de realizar o aborto legalmente, foi então que ocorreu, no Texas, o famoso caso Roe v. Wade. Em síntese, o caso aconteceu quando uma jovem engravidou pela terceira vez e, por razões de ser usuária de drogas, não possuía a guarda de seus dois primeiros filhos. Assim, ela alegou falsamente que havia sido estuprada, com a esperança de que as autoridades acreditassem nela, já que em seu estado essa era uma das causas do abortamento legal. As autoridades, entretanto, não acreditaram no relato feito por ela, por carência de provas e, então, a jovem buscou uma clínica de aborto ilegal, porém essa já havia sido interditada e ela não tinha condições de viajar para um lugar em que o aborto fosse permitindo.

Nesse ínterim, duas advogadas, estavam à procura de uma mulher como a jovem que desejava abortar, o que fez com que elas a acolhesse e entrassem em juízo contra as retrógradas leis que delimitavam os casos em que o aborto podia ser praticado. Com isso, elas usaram o nome Jane Roe com o intuito de resguardar a identidade da jovem e, no polo passivo, estava o promotor de justiça Henry Wade, representando o Texas.

Em suma, estava sendo buscada uma decisão erga omnes, a qual foi dada pela Suprema Corte e, assim, a lei texana foi declarada inconstitucional, no âmbito do direito à privacidade da mulher. Sobre isso, destaca-se a decisão do Juiz Harry Blackmun, litteris:

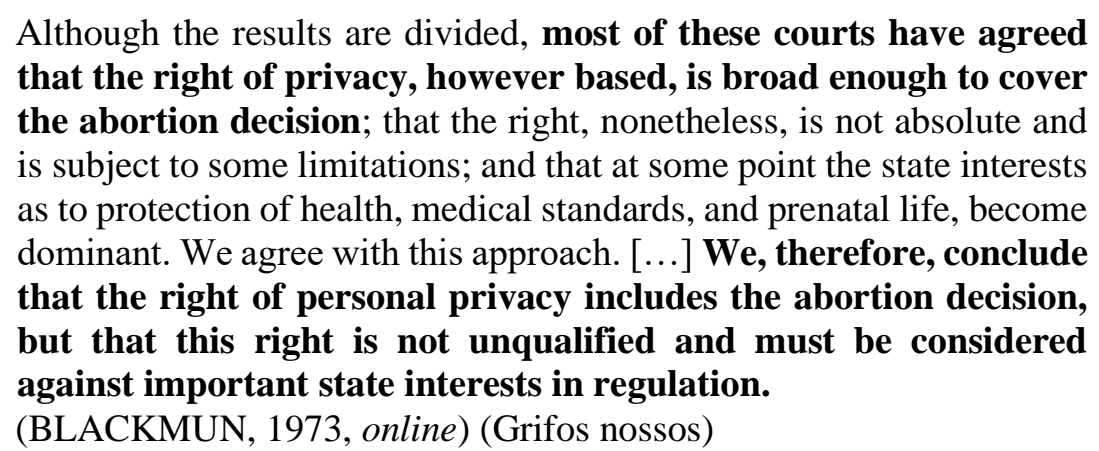

Assim, como visto no excerto, a Suprema Corte também regulou os parâmetros a serem seguidos nas legislações estaduais, isto é, permitiu-se o abortamento livre no 
primeiro trimestre da gestação, no segundo a gestante poderia abortar em função de sua saúde e, a partir do terceiro trimestre, seria legal que os Estados proibissem o abortamento, visto que nesse estágio já há a possibilidade da vida fetal fora do útero da mulher.

Atualmente, os Estados Unidos continuam permitindo o abortamento como um direito fundamental da mulher, até cerca da $24^{\mathrm{a}}$ semana de gravidez, isto é, quando houver a possibilidade de o feto sobreviver fora do útero, a prática não poderá mais ser realizada.

\section{URUGUAI}

Trazendo a discussão para os arredores brasileiros, têm-se o Uruguai que foi o primeiro país da América do Sul a legalizar o aborto e o segundo latino-americano, após a Cuba.

Em 2012, foi promulgada a Lei 18987, a Lei do Aborto, que trata sobre a interrupção voluntária da gravidez. Essa lei, ainda em 2012, foi devidamente regulamentada pelo Decreto n. 375/012. Sobre ela, faz-se importante mencionar o disposto em seus dois primeiros artigos que dizem que o Estado garante o direito de procriação consciente e responsável e, também, promove o exercício dos direitos sexuais e reprodutivos, destacando que o abortamento não é uma forma de controle de nascimento e que este só poderá ser realizado durante as doze primeiras semanas da gravidez indesejada (URUGUAI, 2012, online).

Assim, a lei uruguaia, apesar de ser consideravelmente mais nova, também segue os parâmetros da lei americana. Ademais, constata-se que nesse país, quando a mulher foi vítima de estupro, ela pode abortar até sua $14^{\mathrm{a}}$ semana de gravidez e, nos casos em que houver risco de morte para a gestante ou má formação do feto, não há prazo legal para realizar o abortamento.

Ato contínuo, observa-se que a legalização do aborto no Uruguai trouxe impactos positivos na redução de mortalidade de gestantes, conforme pesquisa realizada pela Organização Mundial da Saúde em 2015. Por sua vez, o Ministério da Saúde do Uruguai, em 2019, apontou que o Uruguai lidera os países da América com as mais baixas taxas de mortalidade materna, o que se deve a Lei do Aborto, segundo o Ministro da Saúde à 
época, Jorge Basso, que afirma, ainda: "Uruguay está a la vanguardia en América en derechos sexuales y reproductivos" (BASSO, 2019, online).

Dessa forma, vê-se que o abortamento legalizado não é uma realidade longínqua, em termos geográficos, do Brasil, visto que países que fazem fronteira com ele já permitem a prática e, igualmente, já apresentam dados positivos em função dessa descriminalização e legalização.

\section{O ABORTAMENTO NA LEGISLAÇÃO BRASILEIRA}

Preliminarmente, é necessário observar o que dispõe o Direito Penal Brasileiro quanto a prática do abortamento. Para tanto, o Código Penal trata essa matéria em seus artigos 124 a 128, mais especificamente na parte dos Crimes Contra A Vida, que dispõem, respectivamente, sobre o aborto provocada pela gestante ou com seu consentimento, aborto provocado por terceiro sem o consentimento dela, aborto provocado com o consentimento da gestante e, por fim, têm-se o art. 127 que dispõe sobre as formas qualificadas do abortamento, que podem ser aumentadas de um terço ou duplicadas.

Ainda, o Código Penal dispõe, em seu art. 128, dois dos três casos em que o abortamento é legalmente permitido, isto é, quando há risco de vida para a gestante (inciso I do art. 128) e quando a gravidez é resultado de estupro (inciso II do art. 128). Quanto à terceira possibilidade de abortamento, têm-se a Arguição de Descumprimento de Preceito Fundamental n. 54 que garantiu a legalização do abortamento quando o feto fosse anencéfalo.

Sobre este caso, é interessante transcrever a ementa da decisão, nesses termos:

ESTADO - LAICIDADE. O Brasil é uma república laica, surgindo absolutamente neutro quanto às religiões. Considerações. FETO ANENCÉFALO - INTERRUPÇÃO DA GRAVIDEZ - MULHER LIBERDADE SEXUAL E REPRODUTIVA - SAÚDE - DIGNIDADE - AUTODETERMINAÇÃO - DIREITOS FUNDAMENTAIS - CRIME

- INEXISTÊNCIA. Mostra-se inconstitucional interpretação de a interrupção da gravidez de feto anencéfalo ser conduta tipificada nos artigos 124, 126 e 128, incisos I e II, do Código Penal. (Supremo Tribunal Federal, 2012, online)(Grifos apostos)

Nesse sentido, foi criada uma excludente de ilicitude baseada na liberdade sexual e reprodutiva da mulher e, também, sua saúde, dignidade e autodeterminação, tudo sob a ótica dos direitos fundamentais. Além disso, também se constatou a laicidade do Brasil, 
uma vez que é fato que a religiosidade do povo brasileiro, em sua maioria cristã, impede um debate mais amplo sobre a legalização do aborto, que ainda é vista com muitos tabus.

Constata-se, igualmente, que a legislação brasileira quanto o abortamento é bastante ultrapassada, quando comparada aos países mencionados acima, já que eles garantem os direitos da mulher e, também, a emancipação dela que vem aumentando desde o final do século XX.

Sobre o tema, é interessante trazer alguns dados sobre o abortamento no Brasil, os quais corroboram com a obsolescência da legislação brasileira. De acordo com o DataSUS (apud jornal G1), o Sistema Único de Saúde (SUS) atendeu, no primeiro semestre de 2020, cerca de 80,9 mil mulheres após abortos malsucedidos, sejam eles provocados ou espontâneos e, foram realizados pouco mais de 1.000 abortos legais no período de janeiro a junho do mesmo ano. Ainda, foram feitas cerca de 80.948 curetagens e aspirações pelo SUS, ambos procedimentos comumente realizados quando o abortamento é provocado.

Ainda, Scavone (2008) aponta que o abortamento é dificilmente punido no Brasil, o que só reafirma a tese de que a legislação brasileira está ultrapassada. Ao seu turno, torna-se imprescindível destacar o pensamento de Flávia Biroli (2014, p. 38) sobre esse aspecto, nesses termos:

É importante ter em mente que a prática do aborto não é reduzida pela criminalização, mas brutalizada, e tanto mais perigosa para as mulheres quanto maiores são os esforços para fazer cumprir a lei (Boltanski, 2004, p. 2004). A clandestinidade corresponde à realização do aborto em condições precárias quanto mais efetivas são as políticas de repressão, resultando em um número elevado de complicações e de mortes.

Para corroborar com esse pensamento, destaca-se que o número expressivo de abortos também gera custos ao SUS. Estima-se que o sistema público de saúde tem uma despesa maior com abortos malfeitos do que com os abortos legais. Dessa forma, podese inferir que se o abortamento fosse legalizado, tal qual nos países citados acima, o governo brasileiro ainda economizaria as verbas que são utilizadas para tentar salvar a mulher que fez um aborto clandestino que deu errado. Por fim, é importante destacar que não é possível obter dados reais, apenas estimados, dos casos de abortos provocados realizados no Brasil, em razão de sua ilegalidade, que dificulta a apuração de tais números, ou seja, há a subnotificação de casos.

Ainda nesse ínterim, acena-se para o fato de que a legislação penal brasileira é da década de 1940 e que essa sofreu, apenas, pequenas modificações em matéria de 
abortamento. Assim, o Código Penal, nesse quesito, é arcaico, tanto pelo fato de que os abortamentos considerados ilegais por ele ocorrem, tanto por ele não ter acompanhado a emancipação da mulher brasileira perante à sociedade. Sobre a temática, vê-se que esse código foi promulgado quando o Código Civil de 1916 ainda estava em vigência, uma legislação que é reconhecidamente misógina, em que a mulher casada era considerada relativamente incapaz (art. $6^{\circ}$, II) e em que só poderia trabalhar se seu marido permitisse (art. 233, IV e art. 251, VII), além de outras atrocidades incompatíveis com a realidade do século XXI.

Atualmente, as mulheres brasileiras estão investindo cada vez mais em si e em sua formação profissional, assim, o empoderamento feminino faz com que as mulheres optem por ter filhos mais tarde, segundo o Instituto Brasileiro de Geografia e Estatística (apud jornal CNN Brasil). Entretanto, ainda é necessário ver o problema sob a perspectiva de raça, visto que a qualificação profissional não é o principal motivo para as mulheres negras desejarem abortar, como será visto melhor ao final do artigo.

Desse modo, serão analisados, em cada tópico a seguir, as razões pelas quais o direito ao aborto deve ser legalizado, visto que é inegável que se trata não só de uma questão de saúde pública, já que o abortamento ocorre corriqueiramente no país, mas também de um direito sexual e reprodutivo da mulher que, por sua vez, faz parte do direito à autonomia dela.

\section{DIREITOS HUMANOS E FUNDAMENTAIS DA MULHER}

A Declaração Universal dos Direitos Humanos (DUDH) de 1948, foi ratificada pelo Brasil no mesmo ano e, portanto, logo entrou em vigor no país. É nesse documento internacional que estão previstos alguns dos principais direitos que possibilitam a legalização do abortamento no Brasil, como será visto a seguir. Destarte, para iniciar a discussão sobre os Direitos Humanos e a legalização do abortamento é necessário destacar o art. XII da DUDH, que dispõe que não podem haver interferências na vida privada das pessoas, o que inclui intervenções estatais na vida privada da mulher.

Desse modo, a proibição do abortamento nos termos em que hoje ocorre no Brasil violam tal dispositivo internacional, visto que a decisão de abortar ou não é um aspecto da vida privada da mulher, que está sendo duramente reprimido pelo Estado, por razões arcaicas e, também, religiosas, apesar de o Brasil ser um país laico. 
Ainda, para Biroli (2014) e como já supramencionado, os Estados Unidos utilizam o direito à privacidade como uma das facetas ao direito de decidir abortar. Portanto, constata-se que esse já é utilizado como argumento para legalização do abortamento, tendência que deve ser seguida pelo Brasil.

Por sua vez, a Constituição Federal de 1988 traz os direitos fundamentais garantidos a população brasileira, os quais dão subsídios a legalização do abortamento, ou seja, apesar de não serem explícitos, eles estão presentes no texto constitucional. Para tanto, deve ser destacado o art. $5^{\circ}, \mathrm{X}$ da $\mathrm{CF} / 88$ que dispõe sobre a inviolabilidade da vida privada e da intimidade dos brasileiros e, assim, levanta-se o questionamento: proibir o abortamento não é violar a vida privada e a intimidade das brasileiras? Após vasta leitura sobre o assunto, entende-se que sim, proibir o aborto é uma violação da vida privada e da intimidade da mulher grávida, visto que o corpo dela, bem como o que ela deseja fazer com ele, deve ser de sua inteira responsabilidade. É evidente, entretanto, que apesar disso, a mulher deve observar, apenas, o período em que o abortamento seria feito, como será analisado posteriormente.

À vista de breve conclusão, vê-se que o direito à vida, principal argumento utilizado para a não legalização do aborto, já não é um direito absoluto, posto que existem casos em que o abortamento é permitido por lei. Sobre a temática, na década de 1970, Judith Thomson (2012 [1971]) já apontava esse fato em seu texto intitulado "A Defense Of Abortation", como se pode perceber quando ela levanta a hipótese de que para aqueles que são contra o aborto, algumas vidas importam mais que outras, isto é, fetos advindos de casos de estupro por poderem ser abortados, destaco aqui, em algumas legislações, valem menos que aqueles que não podem ser abortados, ou seja, esses segundos possuem mais direitos que os primeiros. Apesar disso, ela também ressalta que as pessoas contra o abortamento, raramente, abrem a exceção para o caso de estupro.

Nesse aspecto, é mister dispor sobre quando a vida efetivamente se inicia, porém, a resposta para essa pergunta não é simples e envolve diversas ciências, como a jurídica, a médica e a religiosa.

É evidente que o catolicismo é predominante no Brasil e, por sua vez, a Igreja Católica condena veementemente o abortamento, já que para ela a vida se inicia na concepção. Apesar disso, o posicionamento da Igreja Católica não pode ser primordial na discussão sobre o abortamento no âmbito jurídico, posto que o Brasil é um país laico. Não obstante, sabe-se que a religião ainda influencia bastante no tema aqui debatido. 
Do ponto de vista médico, não há consenso para a questão, visto que existem várias linhas de pensamento sobre o tema, como: a visão genética, em que a vida começa com a fecundação tal como defendido pela Igreja Católica, a visão embriológica, que considera a terceira semana de gravidez como o início da vida, a visão neurológica, que dispõe que a vida começa com a atividade cerebral, assim como termina quando essa cessa, a visão ecológica, adotada pela Suprema Corte Americana, que defende que a vida só começa quando o feto pode ser individualizado, isto é, quando ele puder viver fora do útero e entre outras.

Por fim, quanto à visão jurídica, adota-se a teoria natalista, uma vez que o Código Civil, em seu art. $2^{\circ}$, diz que a personalidade civil começa com o nascimento com vida. Apesar disso, o início da vida e da personalidade civil são dispositivos diferentes e, ainda, é fato que o Superior Tribunal de Justiça (STJ) reconhece os direitos do nascituro.

Ao seu turno, o Supremo Tribunal Federal (STF) possui entendimento contrário, mais favorável à mulher, nos termos do Habeas Corpus 124.306 - Rio de Janeiro, de 2016, com relatoria do Ministro Marco Aurélio que, em síntese, a criminalização do abortamento no primeiro trimestre de gravidez viola direitos fundamentais da mulher, como seus direitos sexuais e reprodutivos, sua autonomia, sua integridade física e psíquica e, por fim, o princípio da proporcionalidade. Esta decisão é, portanto, primordial para as discussões sobre a legalização do abortamento, principalmente quando se analisa o voto do Ministro-redator Luís Roberto Barroso, pois ele sintetiza, de forma exímia, as razões pelas quais o abortamento deve ser legalizado no Brasil, motivos esses que foram postos no acórdão da decisão supracitada.

Para corroborar com o tema, adiciona-se o estudo de Lucila Scavone (2008) quanto aos direitos reprodutivos que, como ela aponta, estes incluem o direito à saúde da mulher e, portanto, são direitos humanos. Destarte, faz-se necessário destacar que a supracitada autora dispõe que "considerar esse direito na perspectiva da expansão dos direitos humanos - como é tido pela corrente feminista brasileira dos direitos - é aceitar sua ascendência nos direitos individuais que nos remete à apropriação do próprio corpo" (SCAVONE, 2008, p. 677). Dessa forma, confirma-se que o abortamento é um direito humano da mulher e, portanto, necessita ser observado.

Nesse diapasão, observa-se que há a colisão de direitos fundamentais e, portanto, para resolver a lide se deve recorrer, também, ao princípio da proporcionalidade. 


\section{COLISÃO DE DIREITOS E O PRINCÍPIO DA PROPORCIONALIDADE}

À luz do supracitado, é fato que o abortamento ocorre no Brasil, mesmo fora das hipóteses legais, recorrentemente e, portanto, torna-se um problema de saúde pública, posto que grande parte das mulheres que abortam não possuem condições de realizar o abortamento clandestino de forma segura e, consequentemente, são levadas ao SUS para tentar reverter os erros cometidos. Ressalta-se, ademais, que essas são, majoritariamente, mulheres negras, o que inclusive foi constatado na Pesquisa Nacional do Aborto, realizada entre 2010 e 2011 (DINIZ; MEDEIROS, 2012). O resultado da criminalização do abortamento, então, é que inúmeras mulheres morrem anualmente em decorrência de abortos inseguros, o que poderia ser evitado com a descriminalização e legalização da prática, já que elas poderiam abortar de forma segura.

É nesse ponto que colidem dois direitos, quais sejam o direito à vida do nascituro e o direito à autonomia da mulher, que envolve os direitos sexuais e reprodutivos e o direito à privacidade. Igualmente, também há o direito à saúde da mulher, uma vez que quando ela é obrigada a levar adiante uma gravidez indesejada, sua saúde psíquica é atingida de forma descomunal.

Seguidamente, o princípio da proporcionalidade deve ser usado para medir os direitos da mulher, um ser humano já completamente formado e capaz de realizar escolhas, e os direitos do nascituro, que nada mais são que projeções de direitos, visto que o feto é dependente da mulher que o gera e, até determinado ponto, carece até mesmo de sistema nervoso e neurológico, não podendo ser considerado um ser humano individualizado. Desse modo, faz-se o seguinte questionamento: é justo que uma mulher, dotada de direitos, carregue um feto que possui, apenas, probabilidade de direito?

É evidente que não, que não é justo submeter a mulher a tamanha responsabilidade em favor do feto. Apesar disso, também não é justo que a mulher aborte um feto já devidamente formado e com possibilidade de vida extrauterina, tal como apontado pela Suprema Corte americana. É nesse momento que o princípio da proporcionalidade deve ser utilizado.

Assim, deve-se conciliar os direitos de escolha da mulher com os possíveis direitos que um feto poderá vir a ter e, para isso, é necessário determinar até quando a mulher pode abortar, sem que coloque em risco os direitos do feto, caso esse nasça com vida, isto é, deve-se dispor sobre até que período da gestação é seguro que ela aborte. É 
neste ponto que o Direito Comparado pode ser utilizado, ou seja, para conceder parâmetros ao Brasil.

\section{TEORIA FEMINISTA E ABORTAMENTO}

A última parte do presente artigo será focada na Teoria Feminista e o que ela dispõe sobre o abortamento, posto que como foi ressaltado diversas vezes no decorrer do texto, é preciso colocar a autonomia da mulher em ênfase ao se tratar do direito de abortar, visto que as mudanças de uma gestação ocorrerão não somente na parte física de seu corpo, mas também em seu psicológico e, evidentemente, em suas relações sociais e suas economias. Dessa forma, a mulher necessita ter sua autonomia respeitada para decidir se deseja ou não abortar, posto que somente cabe a ela os assuntos relacionados a sua capacidade reprodutiva.

Sobre o abortamento, a teoria feminista pode ser trazida a discussão por Flávia Biroli (2014 , p. 42), sobre a temática :

[...] A afirmação da autonomia das mulheres para decidir sobre a interrupção da gravidez é, assim, algo que toca em questões que não se restringem ao aborto, mas ao funcionamento da democracia, aos espaços e formas da regulação do Estado, às hierarquias e formas toleráveis de dominação, aos direitos individuais e à relação entre todas essas questões e o princípio da laicidade do Estado. [...] Quando seu valor é restrito a um papel, definindo-as por ele, as mulheres se tornam menos do que cidadãs. Essa identidade suspende, também, a diversidade existente entre as próprias mulheres, que podem desejar ser mães ou não, ser heterossexuais ou não, identificar-se em graus distintos ao longo da sua vida com a maternidade como projeto. A autonomia das mulheres está, assim, no centro das disputas relativas ao aborto. $[. .$.$] ( Grifo nosso )$

Dessa forma, resta claro que a Teoria Feminista fundamenta o acesso seguro ao abortamento na autonomia da mulher, fundamental aos Estados democráticos, visto que esse é um direito individual básico que recai, somente, sobre o corpo da mulher. Sendo assim, esse é também um direito político, pois é essencial à democracia.

O abortamento, portanto, concerne um direito da mulher como cidadã, a criminalização da prática é uma assimetria, que impõe limites as mulheres no sentido de dispor de seu próprio corpo, impedimento esse que não ocorre com os homens (BIROLI, 2014). Essa questão, então, evidencia mais uma desigualdade entre homens e mulheres, 
visto que a eles não é imposta tamanha violência de gênero, mas para mulher, essa é tão corriqueira que acabou sendo normalizada e, até, normatizada.

Também nesse enfoque, é importante desmitificar o papel social construído pela sociedade para a mulher, isto é, a mulher como mãe, conceito esse explorado por Flávia Biroli (2014). Essa questão, segundo Scavone (2008), é um símbolo brasileiro histórico cultural que acomete as mulheres, visto que interromper uma gravidez indesejada rompe com todo esse simbolismo retrógado.

Apesar disso, como anteriormente visto, a mulher moderna está cada dia mais independente e, em consequência disso, está se afastando dos ideais retrógrados construídos para ela, ou seja, de que a mulher é menos que um cidadão e que seu papel principal dentro da sociedade é cuidar do lar e procriar. Desse modo, vê-se que as mulheres buscam cada vez mais sua capacitação profissional, o que nem sempre combina com uma gestação. Destarte, faz-se mister que seus direitos sexuais e reprodutivos deixem de ser negligenciados, o que deve ser concretizado ao reconhecer, efetivamente, a sua autonomia de escolha.

Em síntese, torna-se imprescindível ver a mulher como um indivíduo capaz de tomar decisões válidas, tal como ocorre com os homens, uma vez que nos encontramos em uma sociedade onde a discussão sobre gênero é determinante. Sumariamente, esse é o entendimento da Teoria Feminista, ou seja, demonstrar e buscar proporcionar direitos democráticos básicos às mulheres, que vêm sendo negados a elas no Brasil, por meio de sua autonomia, que engloba seu direito de escolher sobre o que acontece em seu próprio corpo.

\section{RELIGIÃO, ESTADO LAICO E O DIREITO AO ABORTAMENTO}

Tal como estudado na Teoria Feminista, um dos principais argumentos à legalização do aborto está no fato de que esse é um direito da mulher que deve ser respeitado em um Estado democrático, uma vez que o abortamento é uma forma da mulher ter autonomia sobre seu próprio corpo.

Desse modo, conforme a Constituição de 1988, em seu art. 5º inciso VI, o Brasil é um Estado laico, o que é essencial para o bom funcionamento de uma democracia. Assim, o Estado brasileiro não possui religião oficial, bem como garante que todas as 
religiões podem ser cultuadas e que, consequentemente, devem ser respeitadas. Não obstante, é fato que, por herança portuguesa, a maior parte da população brasileira se identifica como católica seguida pela religião evangélica, o que reflete na política do país.

É na discussão sobre a legalização do aborto, então, que a religião mais se faz presente na política, já que os juízes, ministros, legisladores e afins deixam a sua fé mover decisões. Para exemplificar essa intromissão, pode-se citar o caso do grupo "Católicas Pelo Direito de Decidir", que teve seu nome questionado judicialmente, já que em sua essência, os católicos não deveriam ser a favor do direito de escolha da mulher em abortar. A ação, que tramitou no Tribunal de Justiça de São Paulo, decidiu em sede recursal que o grupo não poderia usar a palavra "católicas", já que seus objetivos eram contrários aos da Igreja Católica. Na decisão, o relator da ação citou passagens bíblicas.

Esse é, apenas, um pequeno exemplo de como a religião impede uma mudança necessária na legislação do país, uma vez que a atual não é eficaz, visto que seu objetivo primordial é coagir as mulheres a não realizarem o abortamento. Apesar disso, já se pode observar pequenas mudanças quanto o embate entre religião e abortamento, como a vista no supramencionado HC 124.306 de 2016 do STF, que aponta que o Brasil é laico e, por isso, a religião não pode interferir nas decisões judiciais.

\section{VIOLÊNCIA RACIAL E A MULHER NEGRA EM SITUAÇÃO DE ABORTAMENTO}

Este último subtópico tem como objetivo explanar um problema levantado pela Teoria Feminista sobre o abortamento, isto é: o acesso ao aborto, mesmo que fosse legal, é igualitário para mulheres brancas e negras ou para as mulheres ricas e pobres? A raça da mulher influencia seu acesso ao aborto?

Esse tópico se mostra fundamental em se tratando da questão do abortamento no Brasil, uma vez que o Estado brasileiro é acometido pelo racismo estrutural, isto é, as desigualdades, opressões e violências atingem de formas diferentes os brasileiros de acordo com sua raça e tal atrocidade está enraizada e, por vezes, é até naturalizada em nossa sociedade. O racismo estrutural, dessa maneira, também se faz presente nas discussões feministas.

Destarte, como destacam Lima e Cordeiro (2020, p. 103), "Raça e classe constituíram categorias centrais para compreender a prática do aborto, bem como a vida 
reprodutiva das jovens", fato que diz respeito a potencialização da vulnerabilidade das mulheres negras em situação de abortamento, as quais são as maiores vítimas da criminalização do aborto, conforme as autoras supracitadas. Nesse âmbito, torna-se fundamental observar que as mulheres brasileiras possuem experiências diversificadas, pois mesmo que de forma restrita, as mulheres brancas ainda possuem escolhas, o que não ocorre com as mulheres negras e da periferia (LIMA; CORDEIRO, 2020).

Dessa forma, entende-se que o acesso ao aborto não é igualitário para mulheres brancas e mulheres negras, posto que mesmo a sua prática sendo proibida, as mulheres brancas ainda possuem mais oportunidades em realizar um aborto seguro, mesmo que clandestino. É nítido, então, que a raça da mulher influencia no abortamento, bem como as razões pelas quais a mulher negra decide abortar são divergentes das mulheres brancas, isto é, corriqueiramente, essas últimas alegam que escolheram abortar porque a maternidade iria prejudicar sua carreira profissional, enquanto que as primeiras abortam, usualmente, por questões econômicas ou devido a outras várias causas originárias do racismo estrutural.

\section{CONSIDERAÇÕES FINAIS}

Ante todo o exposto, conclui-se que o abortamento sempre ocorreu na sociedade, desde a Grécia Antiga até os dias atuais, como provavelmente continuará ocorrendo, mesmo sendo criminalizado em vários países. Diante disso, vê-se que a legalização do abortamento é crucial no Brasil por diversos motivos, sendo o principal deles o correto funcionamento do Estado Democrático de Direito, posto que a autonomia da mulher, bem como seus direitos reprodutivos, sexuais e humanos devem estar presentes em países democráticos. Ademais, é fato que a legislação sobre abortamento que hoje vigora no Brasil é obsoleta, visto que o Código Penal vigente data de 1940 e não recebeu as devidas atualizações.

Tal obsolescência acena para o fato de que, mesmo constituindo crime, as mulheres brasileiras abortam, porém, sem o mínimo de segurança e higiene, o que é potencializado ao se observar a raça da mulher que está abortando, isto é, o racismo imputado na sociedade brasileira faz com que as mulheres negras e periféricas em situação de abortamento estejam muito mais vulneráveis em comparação às brancas. 
Averiguou-se, ainda, que uma das razões pelas quais a legalização do abortamento não ser mais amplamente discutida em âmbito legislativo e judiciário é devido à religiosidade presente no Brasil aliada à imparcialidade dos juristas brasileiros que, por vezes, deixam sua religião influenciar em suas decisões. Observa-se que essa influência não deveria ocorrer em se tratando de assuntos públicos, posto que o Brasil é um Estado laico, porém, movimentos que apontam essa falha na jurisdição brasileira ainda são escassos.

Nessa perspectiva, utilizou-se o Direito Comparado com o intuito de amparar e fundamentar, coerentemente, a legalização do abortamento em uma democracia, uma vez que os países supracitados são exemplos de legislações modernas sobre o assunto, as quais respeitaram a autonomia das mulheres sobre o seu próprio corpo, bem como o seu direito de escolher.

Ao seu turno, a Teoria Feminista é, igualmente, necessária na discussão abordada, pois ela coloca a mulher no centro do debate, o que hodiernamente não vem ocorrendo. Ademais, a Teoria Feminista não só mostra a necessidade de se concretizar a autonomia da mulher em um Estado Democrático de Direito, tal qual o Brasil, como aponta que o abortamento atinge a mulher de forma exclusiva, ou seja, os homens não sofrem física e nem psicologicamente os efeitos oriundos da decisão de abortar (ou não) um feto e, é em razão disso, que se torna indiscutível a centralização da mulher nessa temática.

Por fim, reafirma-se mais uma vez que a legislação brasileira quanto o abortamento é obsoleta e, portanto, necessita de mudanças urgentes para que essa se torne adequada à democracia, ao Estado laico e, bem como, respeite a autonomia da mulher e seus direitos humanos, sexuais e reprodutivos. Ademais, faz-se necessário, igualmente, observar as discussões sobre o abortamento sob a ótica racial, já que como demonstrado, mesmo que legalizado, o acesso ao abortamento não é igual para mulheres brancas e negras.

\section{REFERÊNCIAS}

ACAYABA, Cíntia; FIGUEIREDO, Patrícia. SUS fez 80,9 mil procedimentos após abortos malsucedidos e 1.024 interrupções de gravidez previstas em lei no $1^{\circ}$ semestre de 2020. G1 São Paulo, 2020. Disponível em: https://g1.globo.com/sp/saopaulo/noticia/2020/08/20/susfez-809-mil-procedimentos-apos-abortos-malsucedidos-e1024-interrupcoes-de-gravidezprevistas-em-lei-no-1o-semestre-de-2020.ghtml. Acesso em: 23 de out. 2021. 
BIROLI, Flávia. Autonomia e justiça no debate sobre aborto: implicações teóricas e políticas. Revista Brasileira de Ciência Política, [S.L.], n. 15, p. 37-68, dez. 2014. FapUNIFESP (SciELO). http://dx.doi.org/10.1590/0103-335220141503. Disponível em:

https://www.scielo.br/j/rbcpol/a/QbtCQW64LCD8f7ZBv4RBSDL/?lang=pt\&format=ht ml. Acesso em: 30 out. 2021.

BRASIL. Supremo Tribunal Federal. ADPF no 54. Relator: Ministro Marco Aurélio. Brasília, DF, 14 de abril de 2012. Diário de Justiça Eletrônico. Brasília, 30 abr. 2013. Disponível em:

https://redir.stf.jus.br/paginadorpub/paginador.jsp?docTP=TP\&docID=3707334. Acesso em: 23 out. 2021.

DAVIS, Angela. Mulheres, Raça e Classe. Tradução: Heci Regina Candiani. 1 ed. São Paulo: Boitempo, 2016. 248 p. Título original: Woman, race and class. ISBN: 978-857559503-9.

DE LUCA, Adriana. Mulheres engravidam cada vez mais tarde no Brasil, diz IBGE. CNN Brasil, 2021. Disponível em: https://www.cnnbrasil.com.br/nacional/mulheresengravidamcada-vez-mais-tarde-no-brasil-diz-ibge/. Acesso em: 23 de out. 2021.

DINIZ, Debora; Medeiros, Marcelo. Itinerários e métodos do aborto ilegal em cinco capitais brasileiras. Ciência \& Saúde Coletiva [online], 2012, v. 17, n. 7, pp. 16711681. Disponível em: https://doi.org/10.1590/S1413-81232012000700002. Acesso em: 15 de nov. 2021.

FERNANDES, Maíra. No Estado laico, juiz não pode atuar como intérprete da fé. Revista Consultor Jurídico, 2020. Disponível em: https://www.conjur.com.br/2020nov-04/escritosmulher-estado-laico-juiz-nao-atuar-interprete-fe. Acesso em: 25 de out. 2021.

HOOKS, Bell. O Feminismo É Para Todo Mundo: Políticas Arrebatadoras. Tradução: Bhuvi Libanio. 12. ed. Rio de Janeiro: Rosa dos Tempos, 2020. 176 p. Título original: Feminism Is For Everybody: Passionate Politics. ISBN: 978-85-01-11559-1.

LIMA, Nathália Diórgenes Ferreira; CORDEIRO, Rosineide de Lourdes Meira. Aborto, Racismo e Violência: reflexões a partir do feminismo negro. Em Pauta, Rio de Janeiro, v. 18, n. 46, p. 101-117, 2020. Semestral. Disponível em:

https://www.epublicacoes.uerj.br/index.php/revistaempauta/article/view/52010. Acesso em: 02 nov. 2021.

MARANHÃO, Fabiana. Brasileira conta como é aborto no Uruguai: "No Brasil, quase fui presa”. UOL, 2017. Disponível em:

https://noticias.uol.com.br/saude/ultimasnoticias/redacao/2017/11/15/aborto-nouruguai-e-legal-e-seguro-mas-doloroso-relatabrasileira.htm. Acesso em: 16 de out. 2021.

MUTO, Eiza; Narloch; Leandro. Quando a vida começa?. Revista Super Interessante, 2016. Disponível em: https://super.abril.com.br/ciencia/vida-o-primeiro-instante/. Acesso em: 24 de out. 2021. 
URUGUAY lidera en América baja de indicadores de mortalidad materna y embarazo adolescente. Ministerio Del Salud Pública, 2019. Disponível em:

https://www.gub.uy/ministerio-salud-publica/comunicacion/noticias/uruguay-lideraamericabaja-indicadores-mortalidad-materna-embarazo. Acesso em: 16 de out. 2021.

RAMOS, Rahellen. Aborto: entenda essa questão. Politize!, 2020. Disponível em: https://www.politize.com.br/aborto-entenda-essa-questao/. Acesso em: 13 de out. 2021.

Roe v. Wade, 410 U.S. 113 (1973). Justicia US Supreme Court. Disponível em: https://supreme.justia.com/cases/federal/us/410/113/. Acesso em: 14 de nov. 2021.

SARMENTO, Daniel. Legalização do aborto e Constituição. Revista de Direito Administrativo, v. 240, p. 43-82, 2005.

SCAVONE, Lucila. Políticas Feministas do Aborto. Revista Estudos Feministas, v. 16, n. 2, p. 675-680. Disponível em:

https://www.scielo.br/j/ref/a/zMtWmSKVWgNMKNtMWS3LV3b/?lang=pt\#. Acesso em: 03 de nov. 2021.

SCHOR, Néia; ALVARENGA, Augusta T. de. O aborto: um resgate histórico e outros dados. Journal of Human Growth and Development, [s. 1.], v. IV (2), p. 12-17, 19 dev. 1994 DOI: https://doi.org/https://doi.org/10.7322/jhgd.38132. Disponível em: https://www.revistas.usp.br/jhgd/article/view/38134/40867. Acesso em: 14 de out. 2021.

THOMSON, Judith Jarvis. Uma defesa do aborto. Revista Brasileira de Ciência Política [online]. 2012, n. 7, pp. 145-163. Disponível em: https://doi.org/10.1590/S010333522012000100008 . Acesso em: 06 de nov. 2021.

URUGUAI. Ley N 18987 : LEY SOBRE INTERRUPCION VOLUNTARIA DEL EMBARAZO. LEY DEL ABORTO. Disponível em:

https://www.impo.com.uy/bases/leyes/18987-2012. Acesso em: 16 de out. 2021.

\section{Recebido em: 20/11/2021}

Aprovado em: 10/12/2021

Publicado em: 14/12/2021 